\title{
Assessment of the Allelopathic Potential of an Invasive Alien Weed Hyptis suaveolens (L.) Poit. on Germination of Oryza sativa L.
}

\author{
Atia Arzoo ${ }^{1}$, Akhtari Khatoon ${ }^{1}$, Sandeep Kumar Nayak ${ }^{1}$, Ashirbad Mohapatra ${ }^{2}$ and Kunja Bihari Satapathy ${ }^{1}$ \\ 1. P.G. Department of Botany, Utkal University, Bhubaneswar 751004, Odisha, India \\ 2. Sri Jayadev College of Education and Technology, Bhubaneswar 752 101, Odisha, India
}

\begin{abstract}
Hyptis suaveolens (L.) Poit. is an invasive alien weed commonly known as "Bana tulsi” in Odisha belonging to the family Lamiaceae and widely distributed in different parts of India. The leaves of the plant have been reported to be used as stimulant, carminative, sudorific and also as a cure for parasitic cutaneous diseases besides the crude leaf extract is reported to be used against colic and stomach-ache. The leaves are the source of different alkaloids, terpenes and volatile oils having allelopathic effect. In view of this the present work was carried out with an aim to investigate the allelopathic effect upon germination of rice (Oryza sativa L.). The result indicated that the higher concentration of the leaf leachate could decrease the percentage of germination besides identified as a potential bio-herbicide.
\end{abstract}

Key words: Allelopathy, Hyptis suaveoles, Oryza sativa.

\section{Introduction}

Rice is the main staple food in the Asia and the Pacific region, providing almost 39\% of calories [1]. In transplanted rice, uncontrolled weed growth caused $33 \%-45 \%$ reduction in grain yield of rice besides impairment of the quality of the grain. Rice (Oryza sativa L.) is traditionally grown in India by manual transplanting of seedlings into puddled soil. However, growers are shifting towards direct-seeded rice systems, which are considered more profitable and sustainable than flooded transplanted rice because they require less water and man days than the traditional method of transplanted rice [2].

Invasive alien weed species are the plants whose introduction or spread threatens the environment, the agricultural economy, human health and biodiversity of a region. A number of invasive alien weeds have been reported to have curative properties which are

Corresponding author: Kunja Bihari Satapathy, associate professor, research fields: environmental biotechnology and microbiology. utilized in the traditional systems of medicines. Hyptis suaveolens (L.) Poit. is used by the traditional population in several parts of the world to treat inflammation, gastric ulcer and infection and is used as a crude drug to relieve symptoms related with gastric ulcer or gastritis. Hyptis is a rigid annual herb of aggressive nature [3] and it contains several chemical constituents such as carbohydrate, phenol, tannin, saponin, alkaloid, steroid and flavonoid etc. which are responsible for its medicinal properties.

Allelopathy is defined as the direct or indirect harmful or beneficial effects of one plant on another through the release of certain chemical compounds into the environment [4]. In many cases, weeds are responsible to threaten the biodiversity of landscapes, forests, national parks and water bodies besides depletion of crop productivity and deteriorating environment. In opposite to negative impacts, weeds are also considered as valuable resource in view of their various uses [5, 6]. 

suaveolens (L.) Poit. on Germination of Oryza sativa L.

\section{Methodology}

The leaves of Hyptis suaveolens (L.) Poit. were collected from Kapilash forest region of Dhenkanal district, Odisha, were shade dried and leachate was prepared by soaking $50 \mathrm{~g}$ of dried powdered leaves in $1,000 \mathrm{~mL}$ of distilled sterile water for $48 \mathrm{hrs}$ at $26 \pm$ $10{ }^{\circ} \mathrm{C}$ and normal pressure. The solutions were filtered through whatman No.1 filter paper and the leachate of $50 \mathrm{~g}$ in 1,000 mL was diluted to 40, 30, 20 and $10 \mathrm{~g} / \mathrm{L}$. The different dilutions of leachate were tested against the control (distilled water) on the growth of the test crop Oryza sativa L. obtained from National Rice Research Institute, Cuttack, India. Seeds of Oryza sativa L. were surface sterilized with $0.1 \%$ of mercuric chloride and washed thoroughly with distilled water. Fifty uniform sized seeds were placed in petridishes with different concentrations of leachate and one with control at a constant temperature at $26{ }^{\circ} \mathrm{C}$. Seeds were irrigated with $30 \mathrm{~mL}$ of test solutions and distilled water twice a day. Each treatment was replicated five times. The number of seeds germinated in each treatment was counted on fourth day after sowing and the total germination percentage was calculated. Vigour index [7],
Tolerance index of seedlings [8] and percentage of phytotoxicity were also calculated.

\section{Results and Discussion}

The data on the effect of the leaf residues revealed that the percentage of germination was significantly decreased from $96.5 \%$ to $19.2 \%$ with the increase in leachate concentration of 0.0 to $50 \mathrm{~g} / \mathrm{L}$ respectively. Similarly the radicle length of the seedling was also decreased from $5.6 \mathrm{~cm}$ to $0.2 \mathrm{~cm}$ with an increase in the concentration of the leachate i.e. 0.0 to $50 \mathrm{~g} / \mathrm{L}$ respectively. Seedling vigour index was found to be decreased with the increase in the concentration of the leachate under use. Similarly the percentage of phytotoxicity was increased with increasing concentration of the leachate. The data of the present investigation are presented in Tables 1 and 2.

Reduction in plant growth was earlier reported under allelopathic stress [9-11]. Similar reports on the growth of tomato, radish, cucumber and barnyard grass being inhibited via water extract of Lantana camara [12], and inhibition in root initiation, number of roots and root length of hypocotyls of mung bean and pea was observed when treated with leaf extract

Table 1 Effect of aqueous extract of Hyptis suaveolens on seed germination of rice.

\begin{tabular}{lllll}
\hline Treatments & No. of seed germinated & No. of seed shown & Percentage of germination & Percentage of inhibition \\
\hline Control & $96.4 \pm 0.670$ & 100 & 96.4 & 3.6 \\
$10 \mathrm{~g} / \mathrm{L}$ & $62 \pm 0.567$ & 100 & 62 & 38 \\
$20 \mathrm{~g} / \mathrm{L}$ & $43 \pm 0.671$ & 100 & 43 & 57 \\
$30 \mathrm{~g} / \mathrm{L}$ & $30.4 \pm 0.671$ & 100 & 30.4 & 69.6 \\
$40 \mathrm{~g} / \mathrm{L}$ & $23.2 \pm 0.439$ & 100 & 23.2 & 76.8 \\
$50 \mathrm{~g} / \mathrm{L}$ & $19.2 \pm 0.439$ & 100 & 19.2 & 80.8 \\
\hline
\end{tabular}

Values of 5 replicate \pm SEM.

Table 2 Effect of aqueous extract of Hyptis suaveolens on radicle length, seedling vigour index and percentage of phyto-toxicity in Oryza sativa L. after 4 days of treatment.

\begin{tabular}{lllll}
\hline Treatments & Germination percentage & Radicle length $(\mathrm{cm})$ & Seedling vigour index & Percentage of phyto-toxicity \\
\hline Control & 96.4 & $5.6 \pm 0.136$ & 539.84 & 0 \\
$10 \mathrm{~g} / \mathrm{L}$ & 62 & $3.1 \pm 0.084$ & 192.2 & 44.64 \\
$20 \mathrm{~g} / \mathrm{L}$ & 43 & $2.6 \pm 0.068$ & 111.8 & 53.57 \\
$30 \mathrm{~g} / \mathrm{L}$ & 30.4 & $1.5 \pm 0.079$ & 45.6 & 73.21 \\
$40 \mathrm{~g} / \mathrm{L}$ & 23.2 & $0.8 \pm 0.067$ & 18.56 & 85.71 \\
$50 \mathrm{~g} / \mathrm{L}$ & 19.2 & $0.2 \pm 0.047$ & 3.84 & 96.42 \\
\hline
\end{tabular}

Values of 5 replicates \pm SEM. 

suaveolens (L.) Poit. on Germination of Oryza sativa L.

of Eucalyptus urophylla [13]. Literature also revealed about the inhibitory effect of the aqueous extract of five weed species namely Alternanthera sessilis, Echinochola colona L., Tridax procumbens L., Parthenium hysterophorous L. and Cyprus tuborus upon germination of crop plants like black gram, cluster bean, cotton, ladies finger and rice. The findings of the present study also confirmed the weedicidal effect of the aqueous extract of Hyptis suaveolens thereby showing its allelopathic potential [14].

\section{Conclusion}

The present investigation indicated that Hyptis suaveolens had a strong allelopathic effect upon germination of rice. An increasing trend in phytotoxicity was established with an increase in the concentration of the leachate. Hence it is recommended to be removed from crop field before sowing of seed or before plantation. The plant material under study could be a source of potential material for further isolation and identification of allellochemicals to be exploited as natural herbicides to control other weeds. The crude extract or residue of Hyptis suaveolens can be recommended to apply directly in the crop field as bio-herbicide.

\section{Acknowledgment}

The authors are thankful to the University Grants Commission, New Delhi for providing financial assistance to pursue the work and Post Graduate Department of Botany, Utkal University for providing Laboratory facilities during the investigation.

\section{References}

[1] Yaduraju, N. T., and Rao, A. N. 2013. "Implications of Weeds and Weed Management on Food Security and Safety in the Asia-Pacific Region.” In Proceeding of 24th APWSS Conference, Bandung, Indonesia, $13-30$.
[2] Chauhan, B. S. 2012. "Weed Ecology and Weed Management Strategies for Dry-Seeded Rice in Asia." Weed Technology 26: 1-13.

[3] Mudgal, V., Khanna, K. K., and Hazra, P. K. 1997. "Flora of Madhya Pradesh II." Botanical Survey of India 2: 403-4.

[4] Ashrafi, Z. Y., Sadeghi, S., Mashhadi, H. R., and Hassan, M. A. 2008. "Allelopathic Effects of Sunflower (Helianthus Annus) on Germination and Growth of Wild Barley (Hordeum Spontaneum).” Journal of Agriculture \& Technology 4 (1): 219-29.

[5] Kim, K. U., Shin, D. H., and Lee, I. J. 2007. Utility of Weeds and Their Relatives as Resources. Kyungpook National University, Daegu, Korea, 222.

[6] Chandrasena, N. 2014. "Living with Weeds-A New Paradigm.” Indian Journal of Weed Science 46 (1): 96-110.

[7] Abdul Baki, A. A., and Anderson, J. D. 1973. "Vigour Determination in Soybean Seed by Multiple Criteria." Crop Science 3: 630-3.

[8] Turner, R. C., and Marshal, C. 1972. "Accumulation of Zinc by Sub Cellular Fraction of Root Agrostis Tenuis Sixth in Relation to Zinc Tolerance.” New Phytologist 71: 671-6.

[9] Batish, D. R., Singh, H. P., Rana, N., and Kohli, R. K. 2006. "Assessment of Allelopathic Interference of Chenopodium Album through Its Leachates, Debris Extracts, Rhizosphere and Amended Soil." Archives of Agr. and Soil Sci. 52: 705-15.

[10] Singh, N. B., Pandey, B. N., and Singh, A. 2009. "Allelopathic Effects of Cyperus Rotundus Extract in Vitro and ex Vitro on Banana.” Acta Physiol. Planta. 31: 633-8.

[11] Singh, N. B., Singh, A., and Singh, D. 2008. "Autotoxic Effects of Lycopersicon Esculentum.” Allelopathy J. 22 (2): 429-42.

[12] Liu, S. Q., and Jia, Z. H. 2002. "Biological Activity of Aqueous Extract and Volatile Oil from the Leaf Leachate of Lantana Camara and Its Chemical Constituents." Guihaia 22:185-8.

[13] Huang, Z. L., Lin, S. X., Tan, S. M., Lin, S. Y., Yang, G. Q., and Mo, X. Y. 1997. "Effects of Leaf Extracts of Eucalyptus and Other Plants Species on the Rooting of Cutting and Seed Germination of Several Plant Species.” Forest Research 10: 546-50.

[14] Rao, E., Kumary, D. S., and Satyanarayana, A. 1987. "Allelopathic Potential of Hyptis Suaveolens Poit. on Seed Germination of Weeds and Crops." Indian Botanical Reports 6: 77-8. 